\title{
Study of the Effect of Excitation Frequency Variation on the Output of LVDT
}

\author{
Subhashis Maitra \\ Kalyani Government Engineering College \\ Kalyani, Nadia, West Bengal, India
}

\begin{abstract}
Linear Variable Differential Transformer (LVDT) is a displacement transducer which found its widespread application in process industry for the measurement of flow [1], pressure [2], level [3] and temperature [4] in terms of displacement. LVDT is also used to measure force [5], velocity [6] etc. with a high degree of accuracy and reliability. It is well known that the output of LVDT varies linearly with the core motion based on some preassumption as mentioned in different literatures [1] - [8]. However the output is not perfectly linear because of the effect of the construction of the LVDT, material of the core; inter winding capacitance, stray capacitance and self inductances of the primary and secondary. Again the reactance of capacitance and inductance vary with the excitation frequency. Hence, though the output of LVDT is assumed linear with the excitation frequency, but in practice, it varies nonlinearly with the excitation frequency. In this paper, the effect of the excitation frequency on the output of LVDT has been studied and the outputs have been tabulated for the frequency range $50 \mathrm{~Hz}$ to $100 \mathrm{~Hz}$. Also the variation of the output with frequency has been explained graphically.
\end{abstract}

\section{Keywords}

Capacitance, Excitation frequency, Inductances, LVDT, Transducer.

\section{INTRODUCTION}

Researchers have developed different types of displacement transducer in aspect of range of displacement, sensitivity, linearity and accuracy, like linear variable differential transformer (LVDT) [9], capacitive transducer [10], potentiometric transducer [11], resistive transducer [12], etc. Each of these transducers has its drawbacks and imperfections. LVDT is an electro-mechanical displacement transducer [9],[13], which has three coils namely one primary and two secondary. Current in the primary coil induces e.m.f. on the two secondary. The induced e.m.f. depends on the mutual inductances between the primary and the secondary of the LVDT. The mutual inductances again depend on the displacement of the core inside the LVDT and on the material of the core. The resulting output is the difference between the two e.m.f.s induced on both the secondary. The output of the LVDT is controlled by the position of the magnetic core. The two secondary of the LVDT are connected in opposition so that the output should be the difference between the two induced e.m.f. in the two secondary. At the centre of the position measurement stroke, the two secondary voltages of the displacement transducer are equal but because they are connected in opposition, the resulting output from the sensor is zero. As the LVDTs core moves away from centre, the result is an increase in one of the position sensor secondary and a decrease in the other. This results in an output from the measurement sensor. With LVDTs, the phase of the output (compared with the excitation phase) enables the electronics to know which half of the coil the core is in. Since there is no electrical contact across the transducer position sensing element, it offers many advantages over potentiometric linear transducers such as frictionless measurement, infinite mechanical life, excellent resolution and good repeatability. Its main disadvantages are its dynamic response and the effects of the exciting frequency. LVDT can also be used as a secondary transducer in various measurement systems. In those cases, a primary transducer is used to provide a displacement corresponding to the measurand and LVDT is then used to convert the measured displacement into corresponding electrical signal. In case of pressure measurement, displacement of a diaphragm or of the tip of a Bourdon tube is measured using LVDT [14]. Similarly in case of acceleration and force measurement, the displacement of an elastic element subjected to the given force is measured by LVDT [15]. However, the drawback of LVDT is its larger body length and its output is affected by stray magnetic field and excitation frequency as discussed in [16],[17]. To eliminate this error, Dhiman et.al discussed in [16], a strain gauge based displacement sensor that introduced mechanical error in terms of ruggedness. Where, displacement in the range of millimeter is to be measured, capacitive type transducer may be used to measure for its good frequency response. But the drawback of this type of transducer is its nonlinear behavior on account of edge effect and high output impedance on account of its low capacitance value. Hence in this case, the output varies with the excitation frequency resulting an erroneous result. Different literatures on LVDT so far studied, show the range of measurement, accuracy, reliability, fields of applications etc. but the variation of its output with frequency due to inter winding and stray capacitances has not been discussed so far. In this paper, the effect of stray and inter winding capacitance especially in low range displacement measurement has been discussed. The variations of the output of LVDT with different frequencies have been discussed in tabular form. The plots of the output with frequencies explore how and in which range a specific LVDT can be used with how much degree of accuracy. 


\section{WORKING OF LVDT WITHOUT THE INTER WINDING CAPACITANCES}

The equivalent circuit of an LVDT [1],[2] without considering the stray and inter winding capacitances is shown in Fig.1.

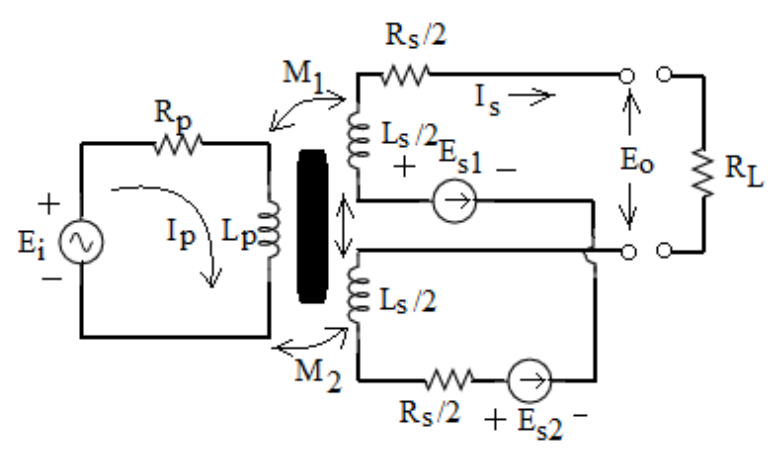

Fig. 1. Equivalent circuit of LVDT.

From Fig. 1, it is clear that the equation for the input, Ei and the output Eo, can be written as

$\mathrm{Ei}=\mathrm{IpRp}+\operatorname{sLpIp}$

$\mathrm{Eo}=\mathrm{Es} 1-\mathrm{Es} 2=(\mathrm{M} 1-\mathrm{M} 2) \mathrm{sI}$

The difference $(\mathrm{M} 1-\mathrm{M} 2)$ varies with the core motion and if it is assumed that the difference varies linearly with the core motion, then it can be written as

$\mathrm{M} 1-\mathrm{M} 2=\mathrm{kd}$, where ' $\mathrm{k}$ ' is the proportionality constant and ' $\mathrm{d}$ ' is the core displacement.

However, the frequency response of the LVDT as stated in $[1]$ is

$\left|E_{o} / E_{i}(j \omega) / d(j \omega)\right|=\frac{\omega k R_{L} /\left[R_{p}\left(R_{S}+R_{L}\right)\right.}{\sqrt{\left[\left\{1-\omega^{2}\left(\tau_{m}^{2}+\tau_{p} \tau_{s}\right)\right\}^{2}+\omega^{2}\left(\tau_{p}+\tau_{s}\right)^{2}\right]}}$

and the phase angle difference between Eo and $\mathrm{Ei}$ is given by, $\theta=90^{0}-\tan ^{-1} \frac{\omega\left(\tau_{p}+\tau_{s}\right)}{1-\omega^{2}\left(\tau_{m}^{2}+\tau_{p} \tau_{s}\right)}$

Where, $\tau_{\mathrm{P}}=\mathrm{L}_{\mathrm{p}} / \mathrm{R}_{\mathrm{p}}, \quad \tau_{\mathrm{s}}=\mathrm{L}_{\mathrm{s}} /\left(\mathrm{R}_{\mathrm{s}}+\mathrm{R}_{\mathrm{L}}\right)$ and $\tau_{\mathrm{m}}^{2}=$ $\frac{\left(M_{1}-M_{2}\right)^{2}}{\left\{R_{p}\left(R_{s}+R_{L}\right)\right\}}$. From (4), it is clear that, at frequency, $\omega=$ $\frac{1}{\sqrt{\tau_{m}^{2}+\tau_{p} \tau_{s}}}$, the phase difference between the excitation voltage and the output is zero degree. Figure 2(a) and (b) show the variation of $E_{0}(j \omega) / d(j \omega)$ and phase angle with frequency respectively, considering $\mathrm{Lp}=6 \mathrm{mH}, \mathrm{Rp}=$ $100 \Omega, \mathrm{M} 1=8 \mathrm{mH}, \mathrm{M} 2=4 \mathrm{mH}, \mathrm{LS}=4 \mathrm{mH}, \mathrm{Rs}=100 \Omega$, $\mathrm{RL}=200 \Omega, \mathrm{d}=2 \mathrm{~mm}$ and $\mathrm{Ei}=100 \mathrm{~V}$.
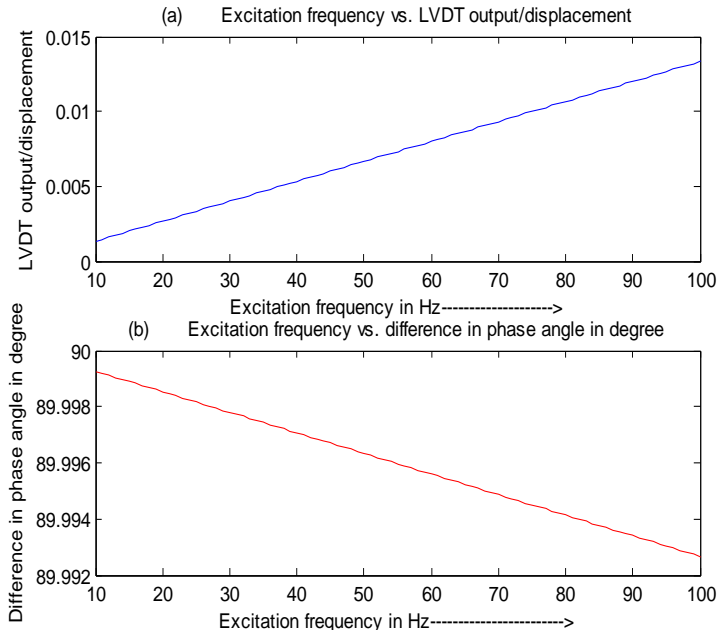

Fig. 2. Variation of output and difference between phase angle with frequency.

From Fig. 2(a), it is clear that $E_{o}(j \omega) / d(j \omega)$ varies linearly with frequency ' $\omega$ '. Though the variation of the difference in phase angle as shown in Fig. 2(b) is nearly equal to 900 , but it varies linearly with ' $\omega$ '. As the displacement increases, since the values of M1 and M2 changes, Eo also changes linearly for a certain displacement and then Eo remains fixed for further displacement on both side. Now as the core moves upward or right direction, the difference of phase angle between the output and the input becomes positive and when it moves downward or left direction, the difference of phase angle become negative. All that have been discussed so far are for the ideal condition of an LVDT, i.e. inter-winding and stray capacitances have not been considered that will be discussed in the next section.

\section{WORKING OF LVDT WITH INTER WINDING AND STRAY CAPACITANCES}

Fig. 3 shows the equivalent circuit diagram of an LVDT considering the inter-winding and stray capacitances. Here $\mathrm{Cp}$ is the equivalent capacitance on the primary side and $\mathrm{Cs}$ is that on the secondary side.

Now for the primary side, using KCL, Ei can be written as

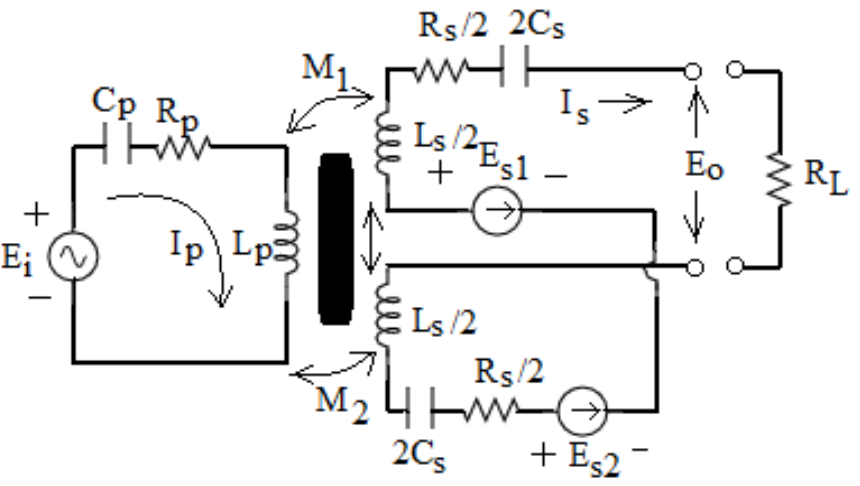

Fig. 3. Equivalent circuit diagram of an LVDT considering the inter-winding and stray capacitance. 
$\mathrm{IpRp}+\frac{1}{\mathrm{C}_{\mathrm{p}}} \int \mathrm{I}_{\mathrm{p}} \mathrm{dt}+\mathrm{Lp} \frac{\mathrm{d} \mathrm{I}_{\mathrm{p}}}{\mathrm{dt}}+(\mathrm{M} 2-\mathrm{M} 1) \frac{\mathrm{d} \mathrm{I}_{\mathrm{s}}}{\mathrm{dt}}=\mathrm{Ei}$

and for the secondary side

$\mathrm{Is}(\mathrm{Rs}+\mathrm{RL})+\frac{1}{\mathrm{C}_{\mathrm{s}}} \int \mathrm{I}_{\mathrm{s}} \mathrm{dt}+\mathrm{Ls} \frac{\mathrm{dI}}{\mathrm{dt}}+(\mathrm{M} 1-\mathrm{M} 2) \frac{\mathrm{dI}_{\mathrm{p}}}{\mathrm{dt}}=0$

Now (5) and (6) can be written as

$\left(\mathrm{Rp}+\frac{1}{\mathrm{sC}_{\mathrm{p}}}+\mathrm{sLp}\right) \mathrm{Ip}(\mathrm{s})-(\mathrm{M} 1-\mathrm{M} 2) \mathrm{sIs}(\mathrm{s})=\operatorname{Ei}(\mathrm{s})$

and

$\left[(\mathrm{Rs}+\mathrm{RL})+\frac{1}{\mathrm{sC}_{\mathrm{s}}}+\mathrm{sLs}\right] \mathrm{Is}(\mathrm{s})+(\mathrm{M} 1-\mathrm{M} 2) \mathrm{sIp}(\mathrm{s})=0$ (8)

From $(8), \operatorname{Is}(\mathrm{s})=-\frac{\left(M_{1}-M_{2}\right) s I_{p}(s)}{\left[\left(R_{s}+R_{L}\right)+\frac{1}{s C_{s}}+s L_{s}\right]}$

Substituting the value of Is(s) in (6) and rearranging we get

$\operatorname{Ei}(s)=\left(R p+\frac{1}{s C_{p}}+s L p\right) I p(s)+\frac{\left(M_{1}-M_{2}\right)^{2} s^{2} I_{p}(s)}{\left[\left(R_{s}+R_{L}\right)+\frac{1}{s C_{s}}+s L_{s}\right]}$

$$
=I p(s)\left[R_{p}\left(R_{s}+R_{L}\right)+\frac{\left(R_{s}+R_{L}\right)}{s C_{p}}+s L_{p}\left(R_{s}+R_{L}\right)+\right.
$$

RpsCp+1s2CpCs+ LpCs+sLsRp+ LsCp+s2LpLs+ (

M1- M2)2s2/ [Rs+ RL+ 1sCs +sLs]

Now, $\operatorname{Eo}(\mathrm{s})=\operatorname{RLIs}(\mathrm{s})$

$$
=-\frac{R_{L}\left(M_{1}-M_{2}\right) s I_{p}(s)}{\left[\left(R_{s}+R_{L}\right)+\frac{1}{s C_{s}}+s L_{s}\right]}
$$

and $(\mathrm{M} 1-\mathrm{M} 2)=\mathrm{Kd}(\mathrm{s})$, where $\mathrm{d}(\mathrm{s})$ is the Laplace of the displacement of the core in the field and $\mathrm{K}$ is a constant.

Hence,

$$
\begin{aligned}
& \mathrm{E}_{0}(\mathrm{~s}) \\
& \overline{E_{i}(s) d(s)} \\
& \frac{R_{L} K s}{R_{p}\left(R_{s}+R_{L}\right)+\frac{\left(R_{s}+R_{L}\right)}{s C_{p}}+s L_{p}\left(R_{s}+R_{L}\right)+\frac{R_{p}}{s C_{p}}+\frac{1}{s^{2} C_{p} C_{s}}+\frac{L_{p}}{C_{s}}+s L_{p} R_{p}+\frac{L_{s}}{C_{p}}+s^{2} L_{p} L_{s}+} \\
& \left(M_{1}-M_{2}\right)^{2} s^{2} \\
& =-\frac{R_{L} K s / R_{p}\left(R_{s}+R_{L}\right)}{1+\frac{1}{s C_{p} R_{p}}+s \frac{L_{p}}{R_{p}}+\frac{1}{s C_{p}\left(R_{s}+R_{L}\right)}+\frac{1}{s^{2} C_{p} C_{s} R_{p}\left(R_{s}+R_{L}\right)}+\frac{L_{p}}{C_{s} R_{p}\left(R_{s}+R_{L}\right)}+\frac{s L_{p}}{\left(R_{s}+R_{L}\right)}} \\
& \frac{L_{s}}{C_{p} R_{p}\left(R_{s}+R_{L}\right)}+\frac{s^{2} L_{p} L_{s}}{R_{p}\left(R_{s}+R_{L}\right)}+\frac{\left(M_{1}-M_{2}\right)^{2} s^{2}}{R_{p}\left(R_{s}+R_{L}\right)}
\end{aligned}
$$

(10)

and this gives

$$
\begin{aligned}
& \frac{E_{0}(j \omega)}{E_{1}(j \omega) d(j \omega)} \\
& \overline{\mathrm{E}_{\mathrm{i}}(\mathrm{j} \omega) \mathrm{d}(\mathrm{j} \omega)} \quad \mathrm{R}_{\mathrm{L}} \mathrm{Ks}^{3} / \mathrm{R}_{\mathrm{p}}\left(\mathrm{R}_{\mathrm{s}}+\mathrm{R}_{\mathrm{L}}\right) \\
& \begin{array}{c}
\mathrm{s}^{2}+\frac{\mathrm{s}}{\tau_{\mathrm{cp}}}+\mathrm{s}^{3} \tau_{\mathrm{lp}}+\frac{\mathrm{s} \beta}{\tau_{\mathrm{cp}}}+\frac{1}{\tau_{\mathrm{cp}} \tau_{\mathrm{csm}}}+\frac{\mathrm{s}^{2} \tau_{\mathrm{lp}}}{\tau_{\mathrm{csm}}}+\mathrm{s}^{3} \tau_{\mathrm{pts}}+\frac{\mathrm{s}^{2} \tau_{\mathrm{lsm}}}{\tau_{\mathrm{cp}}}+\mathrm{s}^{4} \tau_{\mathrm{lp}} \tau_{\mathrm{lsm}} \\
+\mathrm{s}^{4} \tau_{\mathrm{m}}^{2}
\end{array} \\
& \begin{array}{c}
\frac{R_{L} K j \omega^{3} / R_{p}\left(R_{s}+R_{L}\right)}{\left.\frac{1}{\tau_{\text {cp }} \tau_{c s m}}-\omega^{2}\left(1+\frac{\tau_{l p}}{\tau_{\text {csm }}}+\frac{\tau_{\text {lsm }}}{\tau_{\text {cp }}}\right)+\omega^{4}\left(\tau_{l p} \tau_{\text {lsm }}+\tau_{m}^{2}\right)\right]+j\left[\frac{\omega}{\tau_{c p}}(1+\beta)\right.} \\
\left.-\omega^{3}\left(\tau_{l p}+\tau_{p t s}\right)\right]
\end{array}
\end{aligned}
$$

where, $\quad \tau_{c p}=C_{p} R_{p}, \tau_{l p}=\frac{L_{p}}{R_{p}}, \tau_{c s m}=C_{s}\left(R_{s}+R_{L}\right)$, $\tau_{\text {lsm }}=\frac{L_{s}}{\left(R_{s}+R_{L}\right)}, \tau_{p t s}=\frac{L_{p}}{\left(R_{s}+R_{L}\right)}, \beta=\frac{R_{p}}{\left(R_{s}+R_{L}\right)}$ and $\tau_{\mathrm{m}}^{2}=\frac{\left(\mathrm{M}_{1}-\mathrm{M}_{2}\right)^{2}}{\mathrm{R}_{\mathrm{p}}\left(\mathrm{R}_{\mathrm{s}}+\mathrm{R}_{\mathrm{L}}\right)}$

Hence, the magnitude of (11) is

A $\left|\frac{E_{0}(j \omega)}{E_{i}(j \omega) d(j \omega)}\right|=$

$$
\begin{gathered}
\frac{\mathrm{R}_{\mathrm{L}} \mathrm{K} \omega^{3} / \mathrm{R}_{\mathrm{p}}\left(\mathrm{R}_{\mathrm{s}}+\mathrm{R}_{\mathrm{L}}\right)}{\sqrt{ }\left[\frac{1}{\tau_{\mathrm{cp}} \tau_{\mathrm{csm}}}-\omega^{2}\left(1+\frac{\tau_{\mathrm{lp}}}{\tau_{\mathrm{csm}}}+\frac{\tau_{\mathrm{lsm}}}{\tau_{\mathrm{cp}}}\right)+\omega^{4}\left(\tau_{\mathrm{lp}} \tau_{\mathrm{lsm}}+\tau_{\mathrm{m}}^{2}\right)\right\}^{2}+} \\
\left.\left\{\frac{\omega}{\tau_{\mathrm{cp}}}(1+\beta)-\omega^{3}\left(\tau_{\mathrm{lp}}+\tau_{\mathrm{pts}}\right)\right\}^{2}\right]
\end{gathered}
$$

and phase angle between Es and Ei is, $\theta=900-\tan$ $1\left[\frac{\frac{\omega}{\tau_{\mathrm{cp}}}(1+\beta)-\omega^{3}\left(\tau_{\mathrm{lp}}+\tau_{\mathrm{pts}}\right)}{\frac{1}{\tau_{\mathrm{cp}} \tau_{\mathrm{csm}}}-\omega^{2}\left(1+\frac{\tau_{\mathrm{lp}}}{\tau_{\mathrm{csm}}}+\frac{\tau_{\mathrm{lsm}}}{\tau_{\mathrm{cp}}}\right)+\omega^{4}\left(\tau_{\mathrm{lp}} \tau_{\mathrm{lsm}}+\tau_{\mathrm{m}}^{2}\right)}\right]$

So the output of the LVDT is given by, EO = A $\theta$ Eid and $\left|\mathrm{E}_{0}\right|=\mathrm{A}\left|\mathrm{E}_{\mathrm{i}}\right| \mathrm{d}$

It is seen from (12) and (13) that, both ' $A$ ' and ' $\theta$ ' vary with excitation frequency $(\omega)$. The variation of ' $A$ ' with ' $\omega$ ' is shown in Fig. 4 for different values of the constant ' $K$ ', i.e. for three different LVDT. From the Fig., it is clear, that the amplitude of the output of LVDT varies nonlinearly with frequency, though it is linear over a small frequency range. Hence if the inter-winding and stray capacitances are considered, the output can be obtained linear for a fixed range of frequency.

Typical ranges of the self and mutual inductances of the LVDT used to draw the plots in Fig. 4 are given in Table 1 along with the values of the primary and secondary resistances and capacitances. Though the mutual inductances between the primary and the secondary vary with the core displacement, the values of M1 and M2 mentioned here are for displacement, $\mathrm{d}=2 \mathrm{~mm}$.

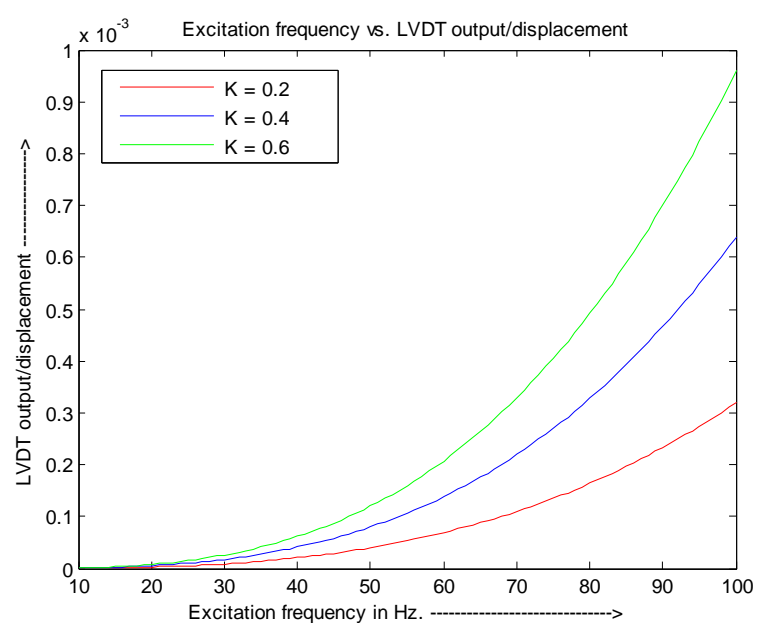

Fig. 4. Variation of ' $A$ ' with excitation frequency ' $\omega$ '.

Table 1. Typical values of the inductances, resistances and capacitances both for primary and secondary of the LVDT used in the experiment

\begin{tabular}{|l|l|l|l|l|l|l|l|c|}
\hline $\mathrm{L}_{\mathrm{P}}$ & $\mathrm{M}_{1}$ & $\mathrm{M}_{2}$ & $\mathrm{~L}_{\mathrm{S} 1}$ & $\mathrm{~L}_{\mathrm{S} 2}$ & $\mathrm{C}_{\mathrm{P}}$ & $\mathrm{C}_{\mathrm{S}}$ & $\mathrm{R}_{\mathrm{P}}$ & $\mathrm{R}_{\mathrm{S}}$ \\
\hline 6 & $1-8$ & $1-8$ & 2 & 2 & 0.2 & 0.4 & 100 & 150 \\
$\mathrm{mH}$ & $\mathrm{mH}$ & $\mathrm{mH}$ & $\mathrm{mH}$ & $\mathrm{mH}$ & $\mu \mathrm{F}$ & $\mu \mathrm{F}$ & $\Omega$ & $\Omega$ \\
\hline
\end{tabular}

From the above table, the values of $\tau_{\mathrm{cp}}, \tau_{\mathrm{lp}}, \tau_{\mathrm{csm}}, \tau_{\mathrm{lsm}}, \tau_{\mathrm{pts}}, \beta$ and $\tau_{\mathrm{m}}$ can be calculated as 
shown in Table 2 considering M1 $=8 \mathrm{mH}, \mathrm{M} 2=4 \mathrm{mH}, \mathrm{LS}$ $=4 \mathrm{mH}, \mathrm{RL}=200 \Omega$.

Table 2. Values of different time constants and ' $\beta$ '

\begin{tabular}{|l|l|l|l|l|l|c|}
\hline $\begin{array}{l}\tau_{c p} \\
\text { sec }\end{array}$ & $\begin{array}{l}\tau_{l p} \\
\text { sec }\end{array}$ & $\begin{array}{l}\tau_{c s m} \\
\text { sec }\end{array}$ & $\begin{array}{l}\tau_{l s m} \\
\text { sec }\end{array}$ & $\begin{array}{l}\tau_{p t s} \\
\text { sec }\end{array}$ & $\tau_{m}$ sec & $\beta$ \\
\hline $2 \mathrm{e}^{-5}$ & $6 \mathrm{e}^{-5}$ & $28 \mathrm{e}^{-5}$ & $\begin{array}{l}1.12 \mathrm{e}^{-} \\
5\end{array}$ & $1.7 \mathrm{e}^{-5}$ & $2.05 \mathrm{e}^{-5}$ & 0.28 \\
\hline
\end{tabular}

So the value of $\mathrm{A}$ is $3.99 \times 10-8$, taking $\omega=50 \mathrm{~Hz}$ and $\mathrm{K}=$ 0.02 . Hence the output of the LVDT for $2 \mathrm{~mm}$ core displacement is $7.98 \times 100 \times 10-8=0.00007 \mathrm{mV}$, where $\mathrm{Ei}$ is taken as $100 \mathrm{~V}$. Fig. 5 shows the LVDT output for different excitation frequency with fixed value of 'd' $(2 \mathrm{~mm})$ and ' $K$ '(2). Fig. 6 shows the difference in phase angle for different frequency.

From Fig. 5, it is clear that the difference in phase angle is greater than that obtained without considering the effect of inter-winding and stray capacitance. Hence, if the core moves upward/right direction or downward/left direction, there will be a significant change in phase angle with the input excitation signal. Hence the design of the lead/lag compensator will be more difficult in case if the interwinding or stray capacitances are considered.

\section{EXPERIMENT AND RESULTS}

Experiment has been performed by measuring the output with excitation frequency for fixed value of ' $d$ '. Here the displacement (d) is kept constant as $2 \mathrm{~mm}$ and the variations of the output for various frequencies are being tabulated in Table 3. The plot corresponding to the results obtained is shown in Fig. 7 where it is compared with the theoretical plot as shown in Fig. 4. It is noticed that the experimental results are nearly similar to the theoretical results as obtained considering the inter-winding and stray capacitances. Also a comparison on the differences of phase angle between input and outputs for different frequencies and for fixed displacement $(\mathrm{d}=2 \mathrm{~mm})$ has been studied using CRO and shown in Table 4 and Fig. 8.

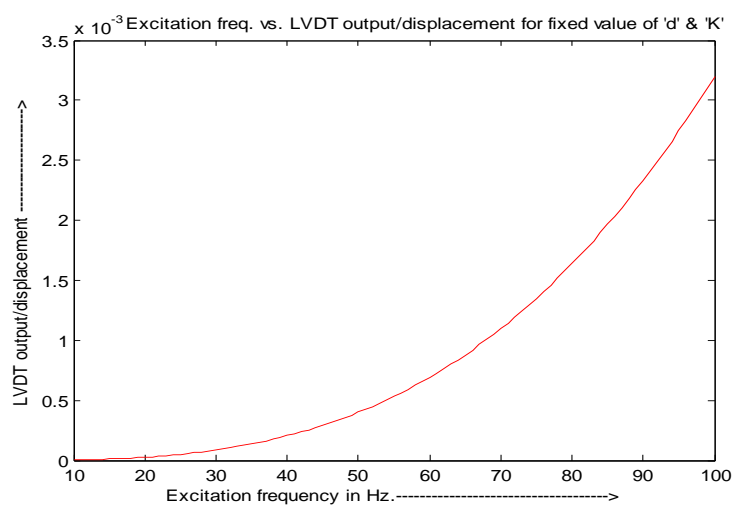

Fig. 5. Variation of LVDT output/displacement with frequency for fixed ' $d$ ' and ' $K$ '.

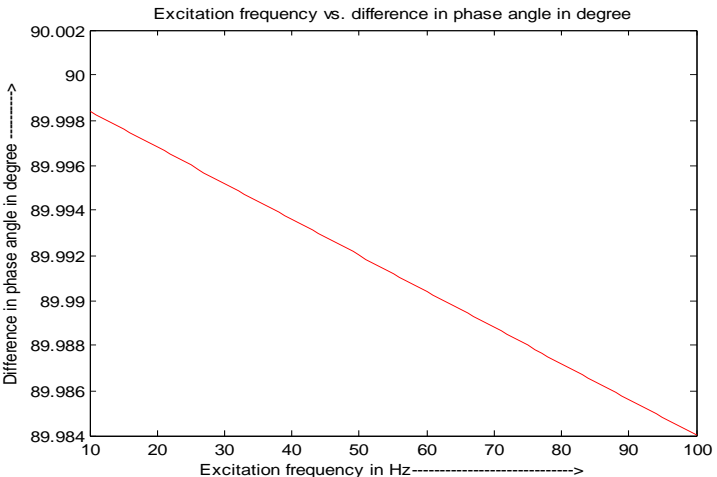

Fig. 6. Difference in phase angle with excitation frequency.

Using equation (12), calculating the parameters $\left(\tau_{\mathrm{cp}}, \tau_{\mathrm{lp}}, \tau_{\mathrm{csm}}, \tau_{\mathrm{lsm}}, \tau_{\mathrm{pts}}, \beta\right)$ of the LVDT using the values shown in Table 1 and taking fixed values of ' $d$ ' $(2 \mathrm{~mm})$, Ei and Eo, the value of $\tau_{m}$ is found out in terms of ' $K$ '. Using this value, the value of (M1 - M2) can be calculated in terms of ' $\mathrm{K}$ '. Then using equation $(\mathrm{M} 1-\mathrm{M} 2)=\mathrm{Kd}$, the ratio of $\mathrm{M} 1$ and $\mathrm{M} 2$ can be calculated and from which, the value of ' $\mathrm{K}$ ' can be found out which is equal to 2 for M1 and $\mathrm{M} 2$ are $8 \mathrm{mH}$ and $4 \mathrm{mH}$ respectively. The plot of the theoretical and practical outputs against excitation frequency for fixed displacement $\mathrm{d}=2 \mathrm{~mm}$ are shown in Fig. 7 with blue and red color respectively. From the Fig., it is clear that the theoretical curve nearly overlaps with experimental curve.

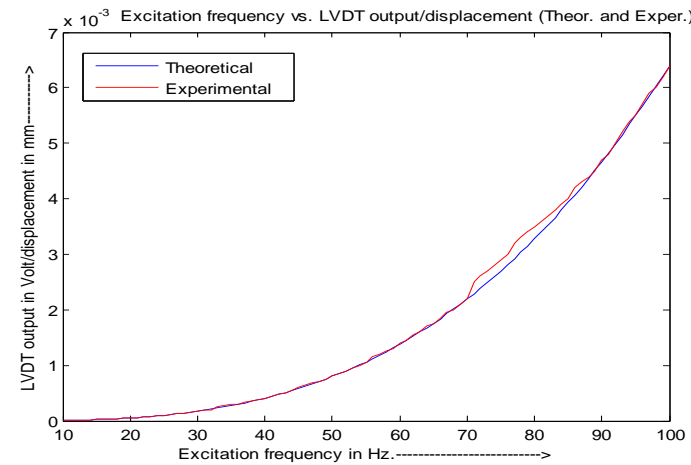

Fig.7. Excitation frequency vs. LVDT output $/ \mathrm{mm}$ displacement both for theoretical and experimental.

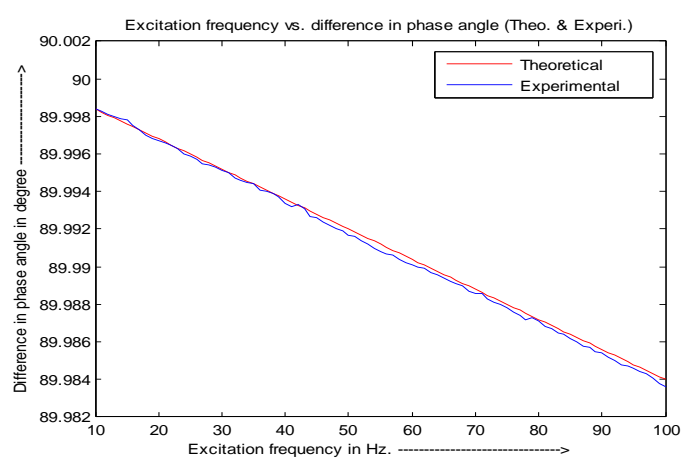

Fig. 8. Differences in phase angle with frequency both for theoretical and experimental. 


\section{CONCLUSION}

From the above discussions and experiment, it is clear that though the output and the phase angle of the output of an LVDT are assumed constant, it is not true for low range measurement. In case of high range measurement, the errors due to inter-winding and stray capacitances can be neglected, but in case low range displacement measurement, the error due to change in excitation frequency is significant, because in that case, the effects of the reactance due to inter-winding and stray capacitances are very much considerable. Since, the results of the experiment show that the output and the difference in phase angle of the output are nearly equivalent, in case of low range measurement, the designer must remember the effect of the unwanted capacitive effects to design lead-lag compensator and the measurement procedure for low range measurement, where accuracy is an important factor, should follow the effects in order to avoid erroneous results.

\section{REFERENCES}

[1] D. Patranabis, Principles of Industrial Instrumentation (Second Edition), 2000, Tata McGraw-Hill Publication.

[2] L.A. Sharif, M. Kilani, S. Taifour, A. J. Issa, E. A. Qaisi, F. A. Eleiwi and O. N. Kamal, "Linear Variable Differential Transformer Design and Verification using MATLAB and Finite Element Analysis", www.intechopen.com.

[3] U.K. Muhammad, S. Umar, "Sensitivity Determination of Linear Variable Differential Transducer (LVDT) in Fluid Level Detection Techniques", International Journal of Modern Engineering Sciences, vol. 2(2), pp(s). $73-83,2013$.

[4] D. L. Knudson, J. L. Rempe, "Evaluation of LVDTs for Use in ATR Irradiation Experiments", Sixth American Nuclear Society International Meeting on Nuclear Plant Instrument, Control and HumanMachine Interface Technologies, NPIC\&HMIT 2009 Knoxville, Tennessee, April 5-9, 2009, on CD-ROM, American Nuclear Society, LaGrange Park, IL (2009).

[5] Saxena, S.C. and Saksena, S. B. L., "A self compensated smart LVDT transducer", IEEE Trans. Inst. \& Meas. Vol. 38 No. 3, 1989, pp. 748-753.

[6] D. J. White, W. A. Take and M. D. Bolton, "Soil deformation measurement using particle image velocimetry (PIV) and photogrammetry," Geotechnique, vol. 53, no. 7, pp. 619-631, 2003.
[7] Pataranabis, D.; Ghosh. S. and Bakshi, C. "Linearining transducer characteristics", IEEE Trans. Inst. \& Meas. Vol. IM 37 No. 1, March 1988, pp. 66-6

[8] Holmberg, P., "Automatic balancing of linear ac bridge circuit for capacitive sensor elements", IEEE Trans. Inst. \& Meas. Vol. 44 No. 3, June 1995, pp. 803-805

[9] R. Mishra, "LVDT: Basic Principle, Theory, Working, Explanation \& Diagram - Linear Variable Differential Transformer" July 21, 2012, https://learnprotocols.Wordpress.com/2012/07/21/lvdtbasic-principle-theory-working-explanation-diagr amlinear-variable-differential-transformer/

[10] A. Fuchs, M. J. Moser, H. Zangl and T. Bretterklieber, "Using Capacitive Sensing to Determine the Moisture Content of Wood Pellets - Investigations and Application, International Journal on Smart Sensing and Intelligent Systems, vol. 2, no. 2, June 2009.

[11] M. Soleimani and M. G. Afshar, "Potentiometric Sensor for Trace Level Analysis of Copper Based on Carbon Paste Electrode Modified with Multi-walled Carbon Nanotubes", Int. J. Electrochemical. Sci., vol. 8, pp(s). $8719-8729,2013$

[12] S.V. Thatthachary, B. George and V.J. Kumar, "A resistive potentiometric type transducer with contactless slide, Seventh International Conference on Sensing Technology (ICST), 3-5 December, 2013, $\mathrm{pp}(\mathrm{s}) .501-505$.

[13] E. O. Doebelin, Measurement Systems-Application \& Design, 5th ed. New York: McGraw-Hill, 2004.

[14] S. K. Mishra and G. Panda, "A novel method for designing LVDT and its comparison with conventional design", Proceedings of the 2006 IEEE Sensors Applications Symposium, pp(s). 129-134, 2006.

[15] P. Chellapandi, V. R. Babu, P. Puthiyavinayagam, S. C. Chetal and B. Raj, "Experimental Evaluation of Integrity of FBR Core under Seismic Events", Journal of Power and Energy Systems, vol. 2, No. 2, pp(s). 582 -589 .

[16] P. K. Dhiman, K. Pal and R. K. Sharma, "Strain Gauge Based Displacement Sensor", Journal of Physical Sciences, Vol. 10, 2006, pp(s). $164-166$.

[17] H. Norton, "Transducer fundamentals," in Handbook of Transducers, Englewood Cliffs, NJ: Prentice Hall, 1989, Ch. 2.

\section{APPENDIX}

Table 3. Variations of the output for various frequencies

\begin{tabular}{|c|l|l|l|l|l|}
\hline $\begin{array}{l}\text { Frequency } \\
\text { in Hz. }\end{array}$ & $\begin{array}{l}\text { LVDT output in } \\
\text { Volt/mm core } \\
\text { displacement } \\
\text { (theoretical) }\end{array}$ & $\begin{array}{l}\text { LVDT output in } \\
\text { Volt/mm cor } \\
\text { displacement } \\
\text { (practical) }\end{array}$ & $\begin{array}{l}\text { Frequency in } \\
\text { Hz. }\end{array}$ & $\begin{array}{l}\text { LVDT output in } \\
\text { Volt/mm } \\
\text { displacement } \\
\text { (theoretical) }\end{array}$ & $\begin{array}{l}\text { LVDT output in } \\
\text { Volt/mm } \\
\text { displacement } \\
\text { (practical) }\end{array}$ \\
\hline 10 & $6.4 \times 10^{-6}$ & $6.5 \times 10^{-6}$ & 56 & $11.24 \times 10^{-4}$ & $11.5 \times 10^{-4}$ \\
\hline 11 & $8.52 \times 10^{-6}$ & $8.8 \times 10^{-6}$ & 57 & $11.85 \times 10^{-4}$ & $12 \times 10^{-4}$ \\
\hline 12 & $11.06 \times 10^{-6}$ & $11.1 \times 10^{-6}$ & 58 & $12.48 \times 10^{-4}$ & $12.5 \times 10^{-4}$ \\
\hline 13 & $14.06 \times 10^{-6}$ & $14.2 \times 10^{-6}$ & 59 & $13.14 \times 10^{-4}$ & $13 \times 10^{-4}$ \\
\hline
\end{tabular}




\begin{tabular}{|c|c|c|c|c|c|}
\hline 14 & $17.56 \times 10^{-6}$ & $17.7 \times 10^{-6}$ & 60 & $13.82 \times 10^{-4}$ & $14 \times 10^{-4}$ \\
\hline 15 & $2.16 \times 10^{-5}$ & $2.2 \times 10^{-5}$ & 61 & $14.53 \times 10^{-4}$ & $14.5 \times 10^{-4}$ \\
\hline 16 & $2.62 \times 10^{-5}$ & $2.7 \times 10^{-5}$ & 62 & $15.25 \times 10^{-4}$ & $15.5 \times 10^{-4}$ \\
\hline 17 & $3.14 \times 10^{-5}$ & $3.2 \times 10^{-5}$ & 63 & $16 \times 10^{-4}$ & $16 \times 10^{-4}$ \\
\hline 18 & $3.73 \times 10^{-5}$ & $3.8 \times 10^{-5}$ & 64 & $16.77 \times 10^{-4}$ & $17 \times 10^{-4}$ \\
\hline 19 & $4.39 \times 10^{-5}$ & $4.4 \times 10^{-5}$ & 65 & $17.57 \times 10^{-4}$ & $17.5 \times 10^{-4}$ \\
\hline 20 & $5.12 \times 10^{-5}$ & $5.2 \times 10^{-5}$ & 66 & $18.39 \times 10^{-4}$ & $18.5 \times 10^{-4}$ \\
\hline 21 & $5.93 \times 10^{-5}$ & $6 \times 10^{-5}$ & 67 & $19.24 \times 10^{-4}$ & $19.5 \times 10^{-4}$ \\
\hline 22 & $6.81 \times 10^{-5}$ & $7 \times 10^{-5}$ & 68 & $20.12 \times 10^{-4}$ & $20 \times 10^{-4}$ \\
\hline 23 & $7.78 \times 10^{-5}$ & $7.9 \times 10^{-5}$ & 69 & $21.02 \times 10^{-4}$ & $21 \times 10^{-4}$ \\
\hline 24 & $8.84 \times 10^{-5}$ & $8.9 \times 10^{-5}$ & 70 & $21.95 \times 10^{-4}$ & $22 \times 10^{-4}$ \\
\hline 25 & $9.98 \times 10^{-5}$ & $10 \times 10^{-5}$ & 71 & $2.29 \times 10^{-3}$ & $2.5 \times 10^{-3}$ \\
\hline 26 & $11.25 \times 10^{-5}$ & $11.5 \times 10^{-5}$ & 72 & $2.39 \times 10^{-3}$ & $2.6 \times 10^{-3}$ \\
\hline 27 & $12.58 \times 10^{-5}$ & $12.5 \times 10^{-5}$ & 73 & $2.49 \times 10^{-3}$ & $2.7 \times 10^{-3}$ \\
\hline 28 & $14.04 \times 10^{-5}$ & $14 \times 10^{-5}$ & 74 & $2.59 \times 10^{-3}$ & $2.8 \times 10^{-3}$ \\
\hline 29 & $15.6 \times 10^{-5}$ & $15.5 \times 10^{-5}$ & 75 & $2.7 \times 10^{-3}$ & $2.9 \times 10^{-3}$ \\
\hline 30 & $17.27 \times 10^{-5}$ & $17.5 \times 10^{-5}$ & 76 & $2.81 \times 10^{-3}$ & $3 \times 10^{-3}$ \\
\hline 31 & $19.06 \times 10^{-5}$ & $19 \times 10^{-5}$ & 77 & $2.92 \times 10^{-3}$ & $3.2 \times 10^{-3}$ \\
\hline 32 & $2.09 \times 10^{-4}$ & $2 \times 10^{-4}$ & 78 & $3.04 \times 10^{-3}$ & $3.3 \times 10^{-3}$ \\
\hline 33 & $2.3 \times 10^{-4}$ & $2.5 \times 10^{-4}$ & 79 & $3.15 \times 10^{-3}$ & $3.4 \times 10^{-3}$ \\
\hline 34 & $2.52 \times 10^{-4}$ & $2.8 \times 10^{-4}$ & 80 & $3.28 \times 10^{-3}$ & $3.5 \times 10^{-3}$ \\
\hline 35 & $2.74 \times 10^{-4}$ & $2.9 \times 10^{-4}$ & 81 & $3.4 \times 10^{-3}$ & $3.6 \times 10^{-3}$ \\
\hline 36 & $2.99 \times 10^{-4}$ & $3 \times 10^{-4}$ & 82 & $3.53 \times 10^{-3}$ & $3.7 \times 10^{-3}$ \\
\hline 37 & $3.24 \times 10^{-4}$ & $3.3 \times 10^{-4}$ & 83 & $3.66 \times 10^{-3}$ & $3.8 \times 10^{-3}$ \\
\hline 38 & $3.51 \times 10^{-4}$ & $3.5 \times 10^{-4}$ & 84 & $3.79 \times 10^{-3}$ & $3.9 \times 10^{-3}$ \\
\hline 39 & $3.79 \times 10^{-4}$ & $3.8 \times 10^{-4}$ & 85 & $3.93 \times 10^{-3}$ & $4 \times 10^{-3}$ \\
\hline 40 & $4.09 \times 10^{-4}$ & $4 \times 10^{-4}$ & 86 & $4.07 \times 10^{-3}$ & $4.2 \times 10^{-3}$ \\
\hline 41 & $4.41 \times 10^{-4}$ & $4.5 \times 10^{-4}$ & 87 & $4.21 \times 10^{-3}$ & $4.3 \times 10^{-3}$ \\
\hline 42 & $4.74 \times 10^{-4}$ & $4.8 \times 10^{-4}$ & 88 & $4.36 \times 10^{-3}$ & $4.4 \times 10^{-3}$ \\
\hline 43 & $5.09 \times 10^{-4}$ & $5 \times 10^{-4}$ & 89 & $4.51 \times 10^{-3}$ & $4.5 \times 10^{-3}$ \\
\hline 44 & $5.45 \times 10^{-4}$ & $5.5 \times 10^{-4}$ & 90 & $4.66 \times 10^{-3}$ & $4.7 \times 10^{-3}$ \\
\hline 45 & $5.83 \times 10^{-4}$ & $6 \times 10^{-4}$ & 91 & $4.82 \times 10^{-3}$ & $4.8 \times 10^{-3}$ \\
\hline 46 & $6.23 \times 10^{-4}$ & $6.4 \times 10^{-4}$ & 92 & $4.98 \times 10^{-3}$ & $5 \times 10^{-3}$ \\
\hline 47 & $6.64 \times 10^{-4}$ & $6.8 \times 10^{-4}$ & 93 & $5.15 \times 10^{-3}$ & $5.2 \times 10^{-3}$ \\
\hline 48 & $7.08 \times 10^{-4}$ & $7 \times 10^{-4}$ & 94 & $5.36 \times 10^{-3}$ & $5.4 \times 10^{-3}$ \\
\hline 49 & $7.53 \times 10^{-4}$ & $7.5 \times 10^{-4}$ & 95 & $5.49 \times 10^{-3}$ & $5.5 \times 10^{-3}$ \\
\hline 50 & $7.99 \times 10^{-4}$ & $8 \times 10^{-4}$ & 96 & $5.66 \times 10^{-3}$ & $5.7 \times 10^{-3}$ \\
\hline 51 & $8.49 \times 10^{-4}$ & $8.5 \times 10^{-4}$ & 97 & $5.84 \times 10^{-3}$ & $5.9 \times 10^{-3}$ \\
\hline 52 & $8.99 \times 10^{-4}$ & $9 \times 10^{-4}$ & 98 & $6.02 \times 10^{-3}$ & $6 \times 10^{-3}$ \\
\hline 53 & $9.53 \times 10^{-4}$ & $9.5 \times 10^{-4}$ & 99 & $6.21 \times 10^{-3}$ & $6.2 \times 10^{-3}$ \\
\hline 54 & $10.07 \times 10^{-4}$ & $10 \times 10^{-4}$ & 100 & $6.39 \times 10^{-3}$ & $6.4 \times 10^{-3}$ \\
\hline 55 & $10.64 \times 10^{-4}$ & $10.5 \times 10^{-4}$ & 101 & $6.5 \times 10^{-3}$ & $6.6 \times 10^{-3}$ \\
\hline
\end{tabular}

Table 4. Differences in phase angle with frequency (theoretical and experimental)

\begin{tabular}{|c|c|c|c|c|c|}
\hline $\begin{array}{c}\text { Frequency } \\
\text { in Hz. }\end{array}$ & $\begin{array}{c}\text { Difference in phase angle } \\
\text { in degree (Theoretical) }\end{array}$ & $\begin{array}{c}\text { Difference in } \\
\text { phase angle in } \\
\text { degree } \\
\text { (Experimental) }\end{array}$ & $\begin{array}{c}\text { Frequency } \\
\text { in Hz. }\end{array}$ & $\begin{array}{c}\text { Difference in phase angle } \\
\text { in degree (Theoretical) }\end{array}$ & $\begin{array}{c}\text { Difference in phase } \\
\text { angle in degree } \\
\text { (Experimental) }\end{array}$ \\
\hline 10 & 89.9984000007253 & 89.9984 & 56 & 89.9908801343222 & 89.9907 \\
\hline 11 & 89.9982400009654 & 89.9983 & 57 & 89.9907201415164 & 89.9906 \\
\hline 12 & 89.9980800012534 & 89.9981 & 58 & 89.9905601489629 & 89.9904 \\
\hline 13 & 89.9979200015936 & 89.998 & 59 & 89.9904001566662 & 89.9902 \\
\hline 14 & 89.9977600019903 & 89.9979 & 60 & 89.9902401646306 & 89.9901 \\
\hline 15 & 89.9976000024480 & 89.9978 & 61 & 89.9900801728605 & 89.99 \\
\hline 16 & 89.9974400029710 & 89.9975 & 62 & 89.9899201813601 & 89.9899 \\
\hline 17 & 89.9972800035636 & 89.9973 & 63 & 89.9897601901338 & 89.9897 \\
\hline 18 & 89.9971200042301, & 89.997 & 64 & 89.9896001991861 & 89.9896 \\
\hline 19 & 89.9969600049750 & 89.9968 & 65 & 89.9894402085212 & 89.9894 \\
\hline 20 & 89.9968000058026 & 89.9967 & 66 & 89.9892802181434 & 89.9892 \\
\hline 21 & 89.9966400067173 & 89.9966 & 67 & 89.9891202280573 & 89.9891 \\
\hline 22 & 89.9964800077233 & 89.9965 & 68 & 89.9889602382670 & 89.989 \\
\hline 23 & 89.9963200088251 & 89.9963 & 69 & 89.9888002487769 & 89.9887 \\
\hline
\end{tabular}


Communications on Applied Electronics (CAE) - ISSN : 2394-4714

Foundation of Computer Science FCS, New York, USA

Volume 3- No.6, November 2015 - www.caeaccess.org

\begin{tabular}{|c|c|c|c|c|c|}
\hline 24 & 89.9961600100270 & 89.996 & 70 & 89.9886402595914 & 89.9886 \\
\hline 25 & 89.9960000113333 & 89.9959 & 71 & 89.9884802707149 & 89.9886 \\
\hline 26 & 89.9958400127484 & 89.9957 & 72 & 89.9883202821517 & 89.9883 \\
\hline 27 & 89.9956800142766 & 89.9955 & 73 & 89.9881602939061 & 89.9881 \\
\hline 28 & 89.9955200159224 & 89.9954 & 74 & 89.9880003059824 & 89.988 \\
\hline 29 & 89.9953600176900 & 89.9953 & 75 & 89.9880003059824 & 89.9878 \\
\hline 30 & 89.9952000195838 & 89.9951 & 76 & 89.9878403183852 & 89.9876 \\
\hline 31 & 89.9950400216082 & 89.995 & 77 & 89.9876803311186 & 89.9874 \\
\hline 32 & 89.9948800237675 & 89.9947 & 78 & 89.9875203441870 & 89.9872 \\
\hline 33 & 89.9947200260660 & 89.9946 & 79 & 89.9873603575948 & 89.9873 \\
\hline 34 & 89.9944000310983 & 89.9945 & 80 & 89.9872003713464 & 89.9871 \\
\hline 35 & 89.9942400338407 & 89.9944 & 81 & 89.9870403854461 & 89.9868 \\
\hline 36 & 89.9940800367398 & 89.9941 & 82 & 89.9868803998981 & 89.9867 \\
\hline 37 & 89.9939200397999 & 89.994 & 83 & 89.9867204147070 & 89.9865 \\
\hline 38 & 89.9937600430254 & 89.9939 & 84 & 89.9865604298770 & 89.9864 \\
\hline 39 & 89.9936000464206 & 89.9937 & 85 & 89.9864004454125 & 89.9862 \\
\hline 40 & 89.9934400499898 & 89.9934 & 86 & 89.9862404613178 & 89.986 \\
\hline 41 & 89.9932800537375 & 89.9932 & 87 & 89.9860804775973 & 89.9858 \\
\hline 42 & 89.9931200576680 & 89.9933 & 88 & 89.9859204942553 & 89.9857 \\
\hline 43 & 89.9929600617856 & 89.9931 & 89 & 89.9857605112962 & 89.9855 \\
\hline 44 & 89.9928000660946 & 89.9927 & 90 & 89.9856005287243 & 89.9854 \\
\hline 45 & 89.9926400705995 & 89.9926 & 91 & 89.9854405465440 & 89.9852 \\
\hline 46 & 89.9924800753046 & 89.9924 & 92 & 89.9852805647596 & 89.985 \\
\hline 47 & 89.9923200802142 & 89.9922 & 93 & 89.9851205833755 & 89.9848 \\
\hline 48 & 89.9921600853327 & 89.992 & 94 & 89.9849606023959 & 89.9847 \\
\hline 49 & 89.9920000906644 & 89.9919 & 95 & 89.9848006218254 & 89.9846 \\
\hline 50 & 89.9918400962136 & 89.9917 & 96 & 89.9846406416682 & 89.9844 \\
\hline 51 & 89.9916801019849 & 89.9916 & 97 & 89.9844806619286 & 89.9843 \\
\hline 52 & 89.9915201079824 & 89.9914 & 98 & 89.9843206826110 & 89.9841 \\
\hline 53 & 89.9913601142105 & 89.9912 & 99 & 89.9841607037198 & 89.9838 \\
\hline 54 & 89.9912001206736 & 89.991 & 100 & 89.9840007252593 & 89.9836 \\
\hline 55 & 89.9910401273761 & 89.9908 & 101 & 89.983912532134 & 89.9832 \\
\hline
\end{tabular}

